\title{
Análise de coeficiente de trilha para os componentes de produção em $\operatorname{arroz}^{1}$
}

\author{
Path coefficient analysis of rice yield components
}

\author{
Enio Marchezan ${ }^{2}$ Thomas Newton Martin ${ }^{3}$ \\ Fernando Machado dos Santos ${ }^{4}$ Edinalvo Rabaioli Camargo ${ }^{4}$
}

\section{RESUMO}

Com o objetivo de avaliar a influência dos componentes de produção de arroz no rendimento de grãos através da análise de trilha, avaliaram-se 88 genótipos de arroz. em quatro anos agrícolas. Em cada ano, os experimentos foram conduzidos no delineamento em blocos completos casualizados, com quatro repetições. As variáveis analisadas foram: estatura de plantas, rendimento de grãos, esterilidade de espiguetas, número de grãos por panícula, massa de mil grãos e rendimento de engenho. As análises de variância, correlação e de trilha (Path Analysis) foram realizadas para cada variável, utilizando-se o programa computacional GENES. Os genótipos avaliados apresentaram diferenças significativas para todas as variáveis analisadas, nos quatro anos de experimento. A seleção de variáveis deve ser realizada em grupos de cultivares semelhantes entre si e a utilização de um maior número de variáveis possibilita melhores inferências sobre os componentes da produção do arroz. A massa de grãos é o componente de produção que mais afeta o rendimento da cultura do arroz.

Palavras-chave: análise de caminhamento, seleção de variáveis, Oryza sativa $L$.

\section{ABSTRACT}

Eighty eight rice genotypes were evaluated during four years aiming to study the relationship among yield components. In each year, the experimental design was a completely randomized block design with four replications and the variables studied were: plant height, seed yield, spikelet sterility, number of seeds per panicle, 1000 seeds weight and head grains. The estimation of correlations and the path coefficient analysis were conducted with the GENES software.
The genotypes showed significant variability for all the variables analyzed within each one of years. It was concluded that variable selection must be carried out among the cultivars that are more similar and using a greater number of variables allows better inferences about rice yield components. Grain weight was the yield of component that most affected seed yield rice plants.

Key words: path coefficient analysis, variables selection, Oryza sativa $L$.

\section{INTRODUÇÃO}

$\mathrm{O}$ arroz é um dos principais cereais cultivados no Brasil, respondendo por cerca de 1,8\% da produção mundial de arroz e por 52\% da produção do cereal na América do Sul (AZAMBUJA, 2004). As produções de arroz têm evoluído anualmente. Parte desta evolução deve-se ao melhor ambiente em que está se inserindo a cultura, que corresponde a melhorias no manejo do solo, juntamente com a adequada utilização de insumos. Melhoramento das técnicas de cultivo e evolução em programas de melhoramento que disponibilizam cultivares mais adaptadas aos ambientes e, consequientemente, mais produtivas, também são responsáveis pelo acréscimo anual da produção de arroz no Brasil. Segundo o IRGA (2004), o potencial genético de produção das atuais cultivares de arroz se encontra entre 10 e $12 \mathrm{tha}^{-1}$.

\footnotetext{
${ }^{1}$ Marchezan, pesquisador do Conselho Nacional de Desenvolvimento Científico e Tecnológico (CNPq). Martin e Camargo, bolsistas do CNPq. Santos, bolsista do Fundo de Incentivo à Pesquisa (FIPE).

${ }^{2}$ Departamento de Fitotecnia, Centro de Ciências Rurais, Universidade Federal de Santa Maria (UFSM), 97105-900, Santa Maria, RS, Brasil. E-mail: emarch@ccr.ufsm.br

${ }^{3}$ Programa de Pós-graduação em Fitotecnia, Escola Superior de Agricultura "Luiz de Queiroz", Universidade de São Paulo, Brasil. E-mail martin@esalq.usp.br. Autor para correspondência

${ }^{4}$ Curso de Agronomia da UFSM, Santa Maria, RS, Brasil.
} 
A produtividade da cultura de arroz é definida por seus componentes: número de panículas $\mathrm{m}^{2}$, número de grãos por panícula e massa de mil grãos (COSTA et al., 2000). MARCHEZAN (1994) acrescenta ainda que esta última é uma característica mais estável que os demais componentes, pois o tamanho do grão é fisicamente limitado pela lema e pálea. A arquitetura das plantas de arroz interfere diretamente na produção de grãos, devido ao melhor aproveitamento da luz e nutrientes. As plantas classificam-se, quanto à sua arquitetura, em tipo tradicional, tipo intermediário e moderno-filipino. Neste último tipo de arquitetura de plantas, estão a maioria das cultivares utilizadas atualmente, sendo também as que possuem o maior potencial produtivo e resistência ao acamamento (TERRES et al., 2004).

Nos programas de melhoramento genético de cada cultura, a correlação entre as variáveis é importante quando se deseja realizar a seleção simultânea entre as características ou quando o caractere de interesse apresenta baixa herdabilidade ou difícil mensuração ou identificação. Para a solução desse problema, utiliza-se a seleção com base em uma característica de fácil avaliação que está altamente correlacionada com a variável de difícil seleção. Utiliza-se a correlação entre caracteres, pois, através do conhecimento da magnitude do desempenho de uma característica, pode-se avaliar a influência sobre a outra característica. Porém, podem ocorrer alguns equívocos nas estratégias de seleção das características avaliadas a partir da quantificação da magnitude das correlações entre as variáveis. A alta correlação entre dois caracteres pode ser resultado do efeito de um terceiro sobre eles, ou de um grupo de caracteres (CRUZ \& REGAZZI, 1994).

Para entender melhor as associações entre diferentes caracteres, WRIGHT (1921) propôs um método de desdobramento das correlações estimadas em efeitos diretos e indiretos das variáveis sobre uma variável básica. Este método é denominado análise de trilha, análise de caminho ou análise de caminhamento ("Path analysis"). DEWEY \& LU (1959) foram os primeiros pesquisadores a utilizar esta metodologia em plantas. Os mesmos autores destacam que os métodos de correlação linear e regressão múltipla foram os primeiros métodos a serem utilizados nas análises de componentes de rendimento, no entanto, a análise de trilha pode detectar alguns efeitos diretos ou indiretos que atuam sobre o rendimento, que produzem associações particulares. Este método avalia o efeito de uma variável independente $(\mathrm{x})$ sobre uma variável dependente (y), de forma que as outras variáveis (Xi) não possuam influência sobre esse efeito.

Em estudos recentes, mesmo sendo limitados, têm-se utilizado como parâmetros para estimar o rendimento da cultura do arroz, o número de plantas por hectare, o número de panículas por planta, o número de grãos por panícula e a massa de grãos por panícula.

Desta forma, o objetivo deste trabalho foi avaliar, através da análise de trilha, a influência dos componentes de produção de arroz que mais afetam o rendimento de grãos.

\section{MATERIAL E MÉTODOS}

Os dados experimentais utilizados provieram dos ensaios de competição de genótipos de arroz coordenado pelo Instituto Riograndense do Arroz (IRGA), dos anos agrícolas de 1999/2000, 2000/ 2001, 2001/2002 e 2002/2003. Os ensaios foram conduzidos no campo experimental do Departamento de Fitotecnia da Universidade Federal de Santa Maria (UFSM), (latitude: 2943'23" S, longitude: 5343'15" W e altitude: $95 \mathrm{~m}$ ). A área está situada na região fisiográfica da Depressão Central do estado do Rio Grande do Sul e o seu clima é caracterizado, segundo a classificação de Köppen, como Cfa: subtropical úmido, sem estação seca, com temperatura média do mês mais quente superior a $22^{\circ} \mathrm{C}$ (MORENO, 1961). O solo é classificado como Planossolo Hibromórfico eutrófico arênico, pertencente à Unidade de Mapeamento Vacacaí (EMBRAPA, 1999). Os experimentos foram conduzidos no sistema de cultivo convencional com inundação. Foram avaliados 20 genótipos em cada um dos dois primeiros anos (1999/ 2000 e 2000/2001) e 24 genótipos em cada um dos dois últimos anos (2001/2002 e 2002/2003). Os genótipos avaliados em todos os anos não são exatamente os mesmos, devido à inclusão e exclusão de alguns materiais.

A adubação de base foi realizada a lanço e em concordância com as Recomendações de Adubação e Calagem para a Cultura do Arroz nos Estados do Rio Grande do Sul e Santa Catarina (COMISSÃO DE FERTILIDADE DO SOLO RS/SC, 1995). No ano agrícola de 1999/2000, foram aplicados $15 \mathrm{~kg} \mathrm{ha}^{-1} \mathrm{de}$ $\mathrm{N}, 75 \mathrm{~kg} \mathrm{ha}^{-1}$ de $\mathrm{P}_{2} \mathrm{O}_{5}$ e $75 \mathrm{~kg} \mathrm{ha}^{-1} \mathrm{de}_{2} \mathrm{O}$. Para os anos de 2000/2001 e 2001/2002, a adubação consistiu em $10 \mathrm{~kg} \mathrm{ha}^{-1}$ de N, $40 \mathrm{~kg} \mathrm{ha}^{-1}$ de $\mathrm{P}_{2} \mathrm{O}_{5}$ e $40 \mathrm{~kg} \mathrm{ha}^{-1}$ de $\mathrm{K}_{2} \mathrm{O}$. No último ano (2002/2003), foram aplicados $16 \mathrm{~kg}$ $\mathrm{ha}^{-1}$ de $\mathrm{N}, 64 \mathrm{~kg} \mathrm{ha}^{-1}$ de $\mathrm{P}_{2} \mathrm{O}_{5}$ e $96 \mathrm{~kg} \mathrm{ha}^{-1}$ de $\mathrm{K}_{2} \mathrm{O}$. A adubação de cobertura consistiu em $90 \mathrm{~kg} \mathrm{ha}^{-1}$ de $\mathrm{N}$ para os quatro anos de experimento, aplicando-se a 
metade da dose no início do perfilhamento e o restante na iniciação do primórdio floral, na forma de uréia.

As semeaduras foram realizadas de forma mecanizada nos dias 17/11/1999, 20/11/2000, 21/11/ 2001 e 15/11/2002, na densidade média de $150 \mathrm{~kg}$ de sementes ha ${ }^{-1}$. Quanto ao controle de plantas infestantes, foram aplicados os herbicidas Propanil e Clomazone, em 24 dias após a semeadura, no primeiro ano de experimento; Propanil e Azimsulfuron, em 29 dias após a semeadura, no segundo ano; Quinclorac em 21 dias e Azimsulfuron em 29 dias após a semeadura, no terceiro ano de experimento e Clomazone, Propanil, e Quinclorac, em 18 dias após a semeadura para o último ano de experimento.

Os experimentos foram conduzidos no delineamento em blocos completos casualizados, com quatro repetições. As unidades experimentais mediam $5 \mathrm{~m} \times 2 \mathrm{~m}\left(10 \mathrm{~m}^{2}\right)$ e com área útil para estimativa do rendimento de grãos de $3 \mathrm{~m} \times 1,5 \mathrm{~m}\left(4,5 \mathrm{~m}^{2}\right)$. As variáveis analisadas foram: estatura de plantas, determinada por ocasião da colheita, medindo-se em centímetros da superfície do solo até o ápice da panícula, desconsiderando-se a arista (EP), rendimento de grãos ajustados para $13 \%$ de umidade (RG), percentual de esterilidade de espiguetas (EE), número de grãos por panícula (GP), massa de mil grãos (MMG) e rendimento de engenho (RE). As pressuposições do modelo matemático $\left(Y_{i j}=m+b_{j}+t_{i}+e_{i j}\right)$ foram verificados segundo os seguintes testes: teste de não-aditividade de Tukey (aditividade do modelo matemático), teste de seqüências (aleatoriedade dos erros estimados), teste de Bartlett (homogeneidade da variância dos erros estimados entre os genótipos) e teste de normalidade de Lilliefors (normalidade da distribuição dos erros estimados), para todas as variáveis, conforme aplicações de MARQUES (1999). As transformações utilizadas foram a $\log (y)$ e $1 / \sqrt{y}$. As análises de variância, correlação de Pearson e de caminhamento (Path Analysis) foram realizadas para cada variável utilizando-se o programa computacional GENES (CRUZ, 1997), sendo utilizada a matriz de correlação genotípica para obtenção dos efeitos diretos e indiretos.

\section{RESULTADOS E DISCUSSÃO}

Em todos os experimentos, as plantas apresentaram desenvolvimento satisfatório, pois os tratos culturais foram conduzidos de modo que plantas infestantes, pragas e doenças não influenciassem no desenvolvimento das plantas de arroz. A média do rendimento de grãos foi de $8.140 \mathrm{~kg} \mathrm{ha}^{-1}$, sendo superior à produção média da cultura no RS, nos anos agrícolas de execussão, que foi de 5,11 tha ${ }^{-1}$ (CONAB, 2004).

Quanto aos pressupostos do modelo matemático avaliados, verificou-se nos três primeiros anos, que a variável esterilidade de espiguetas violou as pressuposições da homogeneidade de variância do erro e aditividade do modelo e os dados originais sofreram transformação logarítmica. No último ano, as variáveis estatura de plantas e rendimento de grãos violaram a pressuposição de aditividade do modelo e foram transformados com $1 / \sqrt{y}$. As variáveis número de grãos por panícula e massa de mil grãos (2002/ 2003) não apresentaram homogeneidade de variância dos erros e a transformação logarítmica foi utilizada. As variáveis após sofrerem as transformações, atenderam as pressuposições do modelo.

Os genótipos apresentaram diferenças significativas a $5 \%$ de probabilidade de erro em relação a todas as variáveis (Tabela 1). Quanto à significância do efeito de blocos, houve alternância de resultados para as variáveis analisadas nos quatro anos, o que indica a necessidade da utilização de tal delineamento em experimentos de competição de cultivares de arroz. Os reduzidos valores dos erros experimentais conferiram precisões experimentais altas e muito altas, quando comparados com os critérios propostos por LÚCIO et al. (1999). A multicolinearidade foi fraca para as combinações de variáveis realizadas, garantindo-se assim confiabilidade aos resultados obtidos, de modo que as variâncias associadas aos coeficientes de trilha não atinjam valores demasiadamente altos (CARVALHO, 1995). Dessa forma, as observações amostrais das variáveis explicativas ou suas combinações lineares não são correlacionadas.

A variável estatura de planta (EP), apresentou uma relação causa efeito com a variável rendimento de grãos, onde o efeito direto é positivo (1999/2000, 2000/2001 e 2001/2002) sendo mais eficiente para o aumento no rendimento, nesses anos. Porém, no ano agrícola 2002/2003 e no geral isto não se verificou. No primeiro ano de avaliação (1999/ 2000), como o efeito direto das variáveis esterilidade de espiguetas (EE) e rendimento de engenho (RE) apresentou efeito direto negativo, esses caracteres não são determinantes, indicando que a característica estatura de plantas tende a ser mais favorável. Certamente o rendimento de engenho é mais influenciado por eventos climáticos transcorridos durante a execução dos experimentos do que da influência das variáveis fitomorfológicas (Tabela 2). Segundo PEREIRA \& RANGEL (2001) o rendimento 
Tabela 1 - Quadrados médios para as fontes de variação (FV) das variáveis estatura de planta (EP), rendimento de grãos (RG), esterilidade de espiguetas (EE), número de grãos por panícula (GP), massa de mil grãos (MMG), rendimento de engenho (RE), coeficiente de variação experimental (CV\%), médias para os quatro anos agrícolas (1999/2000 a 2002/2003) e na análise geral. UFSM, Santa Maria, RS, 2004.

\begin{tabular}{|c|c|c|c|c|c|c|c|}
\hline \multirow{2}{*}{ FV } & \multirow{2}{*}{ Gl / Var } & $\mathrm{EP}(\mathrm{cm})$ & $\mathrm{RG}\left(\mathrm{t} \mathrm{ha}^{-1}\right)$ & $\mathrm{EE}(\%)$ & GP & MMG (g) & $\mathrm{RE}(\%)$ \\
\hline & & \multicolumn{6}{|c|}{$1999 / 2000$} \\
\hline Bloco & 3 & $177,1725^{*}$ & $0,4927^{\mathrm{ns}}$ & $0,0752^{\mathrm{ns}}$ & $--^{1}$ & -- & $1,2400^{\mathrm{ns}}$ \\
\hline Genótipo & 19 & $86,6655^{*}$ & $3,6847^{*}$ & $0,7416^{*}$ & --- & --- & $58,6100^{*}$ \\
\hline Resíduo & 57 & 5,9996 & 0,2926 & 0,0591 & --- & --- & 2,5850 \\
\hline Média & & 83,80 & 8,750 & 13,73 & --- & --- & 61,25 \\
\hline \multirow[t]{2}{*}{$\mathrm{CV} \%$} & & 2,92 & 6,18 & 9,68 & --- & --- & 2,63 \\
\hline & & \multicolumn{6}{|c|}{$2000 / 2001$} \\
\hline Bloco & 3 & $27,0450^{\mathrm{ns}}$ & $0,8048^{\mathrm{ns}}$ & $0,0469^{\mathrm{ns}}$ & $694,4830^{*}$ & $5,4160^{*}$ & $2,6150^{*}$ \\
\hline Genótipo & 19 & $85,4300^{*}$ & $1,0269^{*}$ & $0,3985^{*}$ & $423,5080^{*}$ & $9,3653^{*}$ & $24,3870^{*}$ \\
\hline Resíduo & 57 & 15,6200 & 0,2981 & 0,0955 & 175,1660 & 1,0600 & 1,4660 \\
\hline Média & & 85,39 & 8,486 & 10,01 & 90,92 & 27,48 & 62,69 \\
\hline \multirow[t]{2}{*}{$\mathrm{CV} \%$} & & 4,63 & 6,43 & 13,90 & 14,56 & 3,75 & 1,93 \\
\hline & & \multicolumn{6}{|c|}{$2001 / 2002$} \\
\hline Bloco & 3 & $45,1660^{*}$ & $5,8850 *$ & $0,2151^{\mathrm{ns}}$ & $565,7800^{\mathrm{ns}}$ & $0,7326^{\mathrm{ns}}$ & --- \\
\hline Genótipo & 23 & $20,2753^{*}$ & $3,3130^{*}$ & $0,5314^{*}$ & $606,9450 *$ & $7,0500^{*}$ & --- \\
\hline Resíduo & 69 & 10,9850 & 0,6540 & 0,1080 & 159,0990 & 1,4500 & --- \\
\hline Média & & 81,21 & 9,90 & 10,43 & 84,99 & 27,78 & --- \\
\hline \multirow[t]{2}{*}{$\mathrm{CV} \%$} & & 4,08 & 8,17 & 14,67 & 14,84 & 4,33 & --- \\
\hline & & \multicolumn{6}{|c|}{$2002 / 2003$} \\
\hline Bloco & 3 & $0,000003^{\mathrm{ns}}$ & $0,0413^{*}$ & $6,7882^{\mathrm{ns}}$ & $0,0056^{\mathrm{ns}}$ & $0,0033^{\mathrm{ns}}$ & $0,7703^{\mathrm{ns}}$ \\
\hline Genótipo & 23 & $0,000013^{*}$ & $0,0035^{*}$ & $76,4995 *$ & $0,0643^{*}$ & $0,0048^{*}$ & $2,2659 *$ \\
\hline Resíduo & 69 & 0,000009 & 0,0012 & 16,2085 & 0,0206 & 0,0026 & 0,3722 \\
\hline Média & & 82,83 & 5,580 & 16,36 & 91,54 & 24,41 & 67,70 \\
\hline \multirow[t]{2}{*}{$\mathrm{CV} \%$} & & 2,68 & 8,14 & 24,60 & 3,19 & 1,58 & 0,90 \\
\hline & & \multicolumn{6}{|c|}{ Análise Geral } \\
\hline Média & & 83,19 & 8,14 & 12,70 & 89,05 & 26,50 & 64,12 \\
\hline $\mathrm{CV} \%$ & & 4,39 & 10,11 & 26,52 & 15,12 & 4,47 & 1,86 \\
\hline
\end{tabular}

${ }^{1}$ variáveis não avaliadas;

$* \mathrm{e}^{\mathrm{ns}}$ : significativo e não significativo pelo teste $\mathrm{F}$ a $5 \%$ de probabilidade, respectivamente.

de engenho é uma característica correlacionada com o tamanho e forma dos grão, sendo altamente influenciada por fatores como atraso na colheita, alta temperatura e pouca umidade durante a fase de maturação, e com os processos de pós colheita, como secagem e armazenamento.

No segundo ano de avaliação (2000/2001), as correlações das variáveis estatura de planta (EP), rendimento de engenho (RE), esterilidade de espiguetas (EE) e massa de mil grãos (MMG) apresentaram causa e efeito com a variável rendimento de grãos, demonstrando que os efeitos diretos elevados indicam uma grande contribuição na seleção para o aumento do rendimento (Tabela 2). Os maiores efeitos diretos foram apresentados pelas variáveis $\operatorname{EP}(0,64)$, RE $(0,52)$, EE $(0,21)$ e MMG $(0,10)$, indicando que a seleção indireta passa a ser eficiente. Já ZAFFARONI
\& SCHENEITER (1991), ao avaliar a cultura do girassol, verificaram que o efeito direto da população foi mascarado pelo efeito negativo do número de sementes por capítulo e massa de grãos, resultando em um baixo coeficiente de correlação.

No terceiro ano de avaliação (2001/2002), as variáveis estatura de planta, número de grãos por panícula e massa de mil grãos apresentaram correlação positiva de causa e efeito direto com a variável rendimento de grãos, além disso, sugere que a seleção indireta deve ser eficiente, pois os efeitos diretos também contribuíram através de vias indiretas para o aumento do rendimento de grãos. Nesse ano, as variáveis que tiveram efeito direto positivo foram GP $(0,63)$, MMG $(0,50)$ e EP $(0,12)$.

No último ano de avaliação (2002/2003), as variáveis que apresentaram o maior efeito total 
Tabela 2 - Estimativas dos efeitos diretos e indiretos entre a variável rendimento de grãos com a estatura de planta, esterilidade de espiguetas, número de grãos por panícula, massa de mil grãos, rendimento de engenho e coeficiente de determinação multivariado $\left(\mathrm{R}^{2}\right)$, em cada ano avaliado e na análise geral. UFSM, Santa Maria, RS, 2004.

\begin{tabular}{|c|c|c|c|c|c|}
\hline Anos & $1999 / 2000$ & $2000 / 2001$ & $2001 / 2002$ & $2002 / 2003$ & Geral \\
\hline Efeitos & \multicolumn{5}{|c|}{ Estatura de Plantas } \\
\hline Direto sobre RG & 0,2223 & 0,6389 & 0,1153 & $-0,5982$ & $-0,0634$ \\
\hline Indireto via EE & $-0,0625$ & 0,0561 & 0,0710 & 0,2385 & 0,0008 \\
\hline Indireto via GP & --- & $-0,2478$ & 0,3762 & 0,9685 & 0,05207 \\
\hline Indireto via MMG & --- & 0,0026 & $-0,0910$ & $-0,0013$ & $-0,0067$ \\
\hline Indireto via RE & 0,1117 & $-0,0624$ & --- & 0,0203 & 0,06651 \\
\hline TOTAL (Cor. Pearson) & 0,2715 & 0,3873 & 0,4716 & 0,6279 & 0,0493 \\
\hline \multirow[t]{2}{*}{ Efeito da variável residual } & 0,68 & & & & \\
\hline & \multicolumn{5}{|c|}{ Esterilidade de Espiguetas } \\
\hline Direto sobre RG & $-0,5882$ & 0,2083 & $-0,5584$ & 0,4692 & $-0,3031$ \\
\hline Indireto via EP & 0,0237 & 0,1720 & $-0,0146$ & $-0,3040$ & 0,0002 \\
\hline Indireto via GP & --- & 0,0126 & 0,1326 & 0,0019 & 0,01811 \\
\hline Indireto via MMG & --- & 0,0253 & 0,2906 & $-0,0242$ & $-0,1814$ \\
\hline Indireto via RE & 0,0814 & $-0,0809$ & --- & $-0,1065$ & $-0,0593$ \\
\hline TOTAL (Cor. Pearson) & $-0,4831$ & 0,3372 & $-0,1498$ & 0,0364 & $-0,5256$ \\
\hline \multirow[t]{2}{*}{ Efeito da variável residual } & 0,53 & & & & \\
\hline & \multicolumn{5}{|c|}{ Número de Grãos por Panícula } \\
\hline Direto sobre RG & --- & $-0,5654$ & 0,6253 & $-1,1925$ & 0,1375 \\
\hline Indireto via EP & --- & 0,2800 & 0,0694 & 0,4858 & $-0,0240$ \\
\hline Indireto via $\mathrm{EE}$ & --- & $-0,0046$ & $-0,1184$ & $-0,0007$ & $-0,0399$ \\
\hline Indireto via MMG & --- & $-0,0407$ & $-0,1407$ & 0,0412 & $-0,1828$ \\
\hline Indireto via RE & --- & 0,0076 & --- & $-0,0429$ & $-0,0539$ \\
\hline TOTAL (Cor. Pearson) & --- & $-0,3231$ & 0,4356 & $-0,7091$ & $-0,1632$ \\
\hline \multirow[t]{2}{*}{ Efeito da variável residual } & 0,77 & & & & \\
\hline & \multicolumn{5}{|c|}{ Massa de Mil Grãos } \\
\hline Direto sobre RG & --- & 0,1002 & 0,5050 & $-0,0768$ & 0,5369 \\
\hline Indireto via EP & --- & 0,01686 & $-0,02078$ & $-0,0105$ & 0,0008 \\
\hline Indireto via $\mathrm{EE}$ & --- & 0,05255 & $-0,3214$ & 0,1477 & 0,1024 \\
\hline Indireto via GP & --- & 0,2297 & $-0,1742$ & 0,64038 & $-0,0468$ \\
\hline Indireto via RE & --- & 0,2297 & --- & $-0,2176$ & 0,1331 \\
\hline \multirow[t]{2}{*}{ TOTAL (Cor. Pearson) } & --- & 0,6290 & $-0,0115$ & 0,4831 & 0,7264 \\
\hline & \multicolumn{5}{|c|}{ Rendimento de Engenho } \\
\hline Direto sobre RG & $-0,4604$ & 0,5211 & --- & $-0,3729$ & $-0,2777$ \\
\hline Indireto via EP & $-0,0539$ & $-0,0766$ & --- & 0,0327 & 0,0152 \\
\hline Indireto via $\mathrm{EE}$ & 0,1040 & $-0,0324$ & --- & 0,1340 & $-0,0648$ \\
\hline Indireto via GP & --- & $-0,0083$ & --- & $-0,1373$ & 0,0267 \\
\hline Indireto via MMG & --- & $-0,0319$ & --- & $-0,0449$ & $-0,2573$ \\
\hline TOTAL (Cor. Pearson) & $-0,4103$ & 0,3719 & --- & $-0,3885$ & $-0,5580$ \\
\hline Efeito da variável residual & 0,64 & & & & \\
\hline $\mathrm{R}^{2}$ & 0,53 & 0,72 & 0,40 & 0,59 & 0,68 \\
\hline
\end{tabular}

positivo com o rendimento de grãos foram a EP e MMG, o que sugere que a seleção direta deva ser eficiente. Porém os caracteres da correlação direta sobre as variáveis foram negativos, indicando assim que o caractere auxiliar não é determinante e que os outros caracteres são mais eficientes. ZAFFARONI et al. (1998) discutem que o número de plantas por hectare aumenta o rendimento até um certo limite, pois existe um obstáculo natural determinado pelas variáveis número de panículas por planta, número de grãos por panícula e massa de mil grãos, que se relaciona negativamente com a primeira variável. Para BLANCO et al. (1993), que utilizou duas cultivares de arroz, as variáveis número de grãos por panícula e massa de mil grãos foram as variáveis que mais influenciaram no rendimento de grãos.

Ciência Rural, v.35 n.5, set-out, 2005. 
Na presença ou ausência de determinadas variáveis, o comportamento de causa e efeito das variáveis sobre o rendimento de grãos é alterado, muitas vezes também modificando sensivelmente as conclusões a respeito dos efeitos de seleção de variáveis em programas de melhoramento. Devido a este fato, realizou-se a análise geral dos quatro experimentos utilizando todas as variáveis.

A análise geral indicou que a variável massa de mil grãos possui correlação alta e o maior efeito direto positivo com o rendimento de grãos. A variável EP não apresenta correlação total positiva, mas muito próximo à nulidade, indicando que a variável auxiliar pode não proporcionar ganhos satisfatórios na variável RG. Dessa forma, indica-se a seleção simultânea de caracteres com ênfase nos efeitos indiretos significativos (CRUZ \& REGAZZI, 1994).

Os coeficientes de determinação multivariados $\left(\mathrm{R}^{2}\right)$ variaram de $0,40(2001 / 2002)$ até $0,72(2000 / 2001)$. Apesar de não existir uma classificação preestabelecida para esses valores, considera-se estes valores como intermediários, que certamente seriam superiores se fossem avaliados grupos similares de genótipos em anos agrícolas como condições mais homogêneas.

Em estudos conduzidos por ZAFFARONI et al. (1998) com nove cultivares de arroz em um ano de avaliação, concluiu-se que o número de grãos por panícula e a massa de mil grãos são os componentes de rendimento que mais influenciaram no rendimento de grãos. Autores como MARTINS et al. (1991) e PEDROSO \& GIORGI (1993) indicam que existe uma compensação na massa de mil grãos quando ocorre um decréscimo na densidade de semeadura e um menor número de panículas por área.

Os resultados obtidos neste trabalho apresentam discordância quanto aos efeitos diretos e indiretos, para os diversos anos. Provavelmente, por se estar avaliando um grande número de genótipos em diversos anos agrícolas, ocorreu uma sobreposição dos efeitos. Desta forma, recomenda-se o agrupamento de materiais semelhantes quanto às variáveis morfofisiológicas, de modo a se obter as influências dos componentes de produção para cada grupo cultivado de arroz. E posteriormente, sejam utilizados os genótipos mais promissores para os cruzamentos.

\section{CONCLUSÃO}

A massa de mil grãos é o componente de produção com maior efeito no aumento do rendimento da cultura do arroz. Em contrapartida, a esterilidade de espiguetas é o componente do rendimento mais influente na redução do rendimento de grãos de arroz. Sendo que estas duas variáveis devem ser priorizadas em programas de melhoramento da cultura.

\section{REFERÊNCIAS}

AZAMBUJA, I.H.V. et al. Aspectos socioeconômicos da produção de arroz. In: GOMES, A. S.; MAGALHÃES JÚNIOR, A.M. de (Ed). Arroz irrigado no sul do Brasil. Brasília, DF: Embrapa, 2004. p.23-44.

BLANCO, P.H. et al. Analisis del crecimiento y componentes de rendimento en cultivares de arroz. In: REUNIÃO DA CULTURA DO ARROZ IRRIGADO, 20., 1993, Pelotas. Anais... Pelotas : Embrapa - CPACT, 1993. p.74-77.

CARVALHO, S.P. de. Métodos alternativos de estimação de coeficientes de trilha e índices de seleção, sob multicolinearidade. Viçosa : UFV, 1995. p.163.

COMISSÃO DE FERTILIDADE DO SOLO-RS/SC. Recomendações de adubação e calagem para o estado do Rio Grande do Sul e Santa Catarina. 3.ed. Passo Fundo: SBCC - Núcleo Regional Sul, EMBRAPA/CNPT, 1995. p.223.

CONAB, Companhia Nacional de Abastecimento. Safras. Séries históricas. Acesso em 22 de novembro de 2004. On line. Disponível em: (http://www.conab.gov.br).

COSTA, E.G.C. et al. Características agronômicas da cultura principal e da soca de arroz irrigado. Ciência e Agrotecnologia, v.24, n.05, p.15-24, 2000.

CRUZ, C.D. Programa Genes: aplicativo computacional em genética e estatística. Viçosa: UFV, 1997. p.442.

CRUZ, C.D.; REGAZZI, A.J. Modelos biométricos aplicados ao melhoramento genético. Viçosa : UFV, 1994. p.390.

DEWEY, D.R.; LU, K.H. A correlation path coefficient analysis of components of crested wheatgrass seed production. Agronomy Journal, Madison, v.51, p.515-518, 1959.

EMBRAPA. Centro Nacional de Pesquisa de Solos (Rio de Janeiro, RJ). Sistema brasileiro de classificação dos solos. Brasília : Embrapa-SPI, 1999. p.412.

IRGA - Instituto Riograndense do Arroz. Arroz RS - O Programa da Produtividade. Acesso em 19 de agosto de 2004. Online. Disponível em: http://www.irga.rs.gov.br/ arrozrs.htm.

LÚCIO, A.D. et al. Classificação dos experimentos de competição de cultivares quanto a sua precisão. Pesquisa Agropecuária Gaúcha, v.5, v.1, p.99-103, 1999.

MARCHEZAN, E. Avaliação de rendimento de engenho de arroz. Lavoura Arrozeira, Porto Alegre, v.47, n.415, p.23, 1994.

MARQUES, D.G. As pressuposições e a precisão dos ensaios de competição de cultivares de milho no estado do Rio Grande do Sul. 1999. 42f. Dissertação (Mestrado em Agronomia) - Centro de Ciências Rurais, Universidade Federal de Santa Maria.

MARTINS, J.F.S. et al. Densidade de semeadura e espaçamento entre linhas para o arroz irrigado cultivado no sistema de 
plantio direto. In: REUNIÃO DA CULTURA DO ARROZ IRRIGADO, 1991, Camboriú. Anais... Balneário Camboriú: EPAGRI, 1991. p.99-101.

MOREno, J.A. Clima do Rio Grande do Sul. Porto Alegre: Secretaria da Agricultura, 1961. p.41.

PEDROSO, B.A.; GIORGI, I.V. Avaliação da cultivar IRGA 416 em seis épocas e três densidades de semeadura. In REUNIÃO DA CULTURA DO ARROZ IRRIGADO, 20. 1993, Pelotas. Anais... Pelotas: Embrapa - CPACT, 1993 p.109-111.

PEREIRA, J.A.; RANGEL, P.H.N. Produtividade e qualidade de grãos de arroz irrigado no Piauí. Ciência e Agrotecnologia, v. 25, n.3, p.569-575, 2001
TERRES, A.L.S. et al. Melhoramento genético e cultivares de arroz irrigado. In: GOMES, A.S.; MAGALHÃES JÚNIOR, A.M. de (Ed). Arroz irrigado no sul do Brasil. Brasília, DF: Embrapa, 2004. p.23-44.

WRIGHT, S. Correlation and causation. Journal of Agricultural Research, v.20, p.557-585, 1921

ZAFFARONI, E.; SCHNEITER, A.A. Sunflower production as influenced by plant type, plant population and row arrangement. Agronomy Journal, v.83, p.113-118, 1991.

ZAFFARONI, E. et al. Análise de caminho nos componentes do rendimento de genótipos de arroz no Rio Grande do Sul. Pesquisa Agropecuária Brasileira, Brasília, v.33, n.1, p.4348. 1998. 